\title{
Direct AC/DC Heating of Oxygen Transport Membranes
}

\author{
Ivan Kovalev ${ }^{1,2}$, Alexander Vorobyev ${ }^{1}$, Artem Bagishev ${ }^{1,3}$, Mikhail Popov ${ }^{1,3, *}$ (1), \\ Marat Sharafutdinov ${ }^{1}$, Alexander Titkov ${ }^{1}$, Sergey Bychkov ${ }^{1}$ and Alexander Nemudry ${ }^{1}$ \\ 1 Institute of Solid State Chemistry and Mechanochemistry SB RAS, 630128 Novosibirsk, Russia; \\ kovalev.ivan.vyacheslavovich@gmail.com (I.K.); voralexmih@mail.ru (A.V.); \\ artembagishev15@gmail.com (A.B.); marat@solid.nsc.ru (M.S.); aitcat@mail.ru (A.T.); \\ bychkov@solid.nsc.ru (S.B.); nemudry@solid.nsc.ru (A.N.) \\ 2 Novosibirsk State Technical University, 630073 Novosibirsk, Russia \\ 3 Novosibirsk State University, 630090 Novosibirsk, Russia \\ * Correspondence: popov@solid.nsc.ru or misha.popov90@gmail.com
}

Received: 29 November 2019; Accepted: 18 December 2019; Published: 19 December 2019

\begin{abstract}
This article is devoted to the development of the direct resistive heating of oxygen transport membranes technique. In this case, DC was selected to perform direct heating. The effect of DC on the oxygen fluxes and the microstructure of the membrane was studied. It is shown that in the short-term experiment with DC, a positive significant effect on the oxygen transport was found, while sample exposure under the influence of DC for a long period of time had a significant negative effect on the microstructure of the membrane.
\end{abstract}

Keywords: oxygen transport membranes; perovskites; direct resistive heating; microtubular membranes

\section{Introduction}

Oxygen-permeable (OP) membranes that are composed of oxides with mixed ionic-electronic conductivity (MIEC) have found applications in various innovative technologies. They have 100\% selectivity and are easily incorporated into the high-temperature processes of the partial oxidation of hydrocarbons, the conversion of methane to synthesis gas, and the dimerization and oxidative pyrolysis of methane, and the production of ethylene and acetylene [1-5].

Earlier [6,7], it was shown the promise of using AC (50 Hz frequency) for the direct heating of hollow fiber membranes (HFMs), which improves their performance and efficiency of temperature control. In this case, the membranes with mixed oxygen-electronic conductivity are both a heater and an oxygen separator.

Here, research is devoted to the development of this technique, namely to the study of AC/DC on the heating process of OP HFMs. The long term stability of the AC/DC-heated $\mathrm{Ba}_{0.5} \mathrm{Sr}_{0.5} \mathrm{Co}_{0.7} \mathrm{Fe}_{0.2} \mathrm{Mo}_{0.1} \mathrm{O}_{3-\delta}$ (BSCFM10) HFMs is studied. It is shown that direct DC heating leads to the degradation of the membrane surface, which negatively affects the functional characteristics of the material.

\section{Experimental}

A powdered BSCFM10 precursor was synthesized by a convenient solid-state reaction. BSCFM10 HFMs were produced by a phase inversion technique. The ceramic precursor was mixed with an N-methyl-2-pyrrolidone solvent (NMP) and a polysulfone binder (PSU) in a ratio of 10:4:1, respectively [6-8]. The slurry was homogenized and degassed by using a Dispermat $₫ L C-55$ (VMA-Getzmann, Germany) over $120 \mathrm{~min}$ at $1500 \mathrm{rpm}$. The slurry was extruded through a spinneret (Figure 1) to make the green bodies of the HFMs. The air gap was $10 \mathrm{~mm}$. 


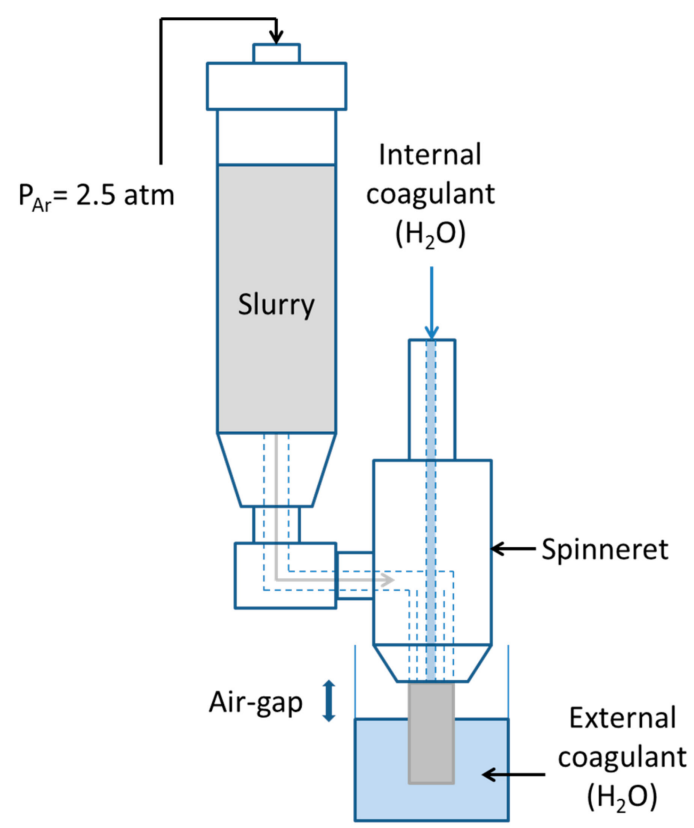

Figure 1. Schematic diagram of the spinneret.

The sintering of the BSCFM10 HFMs was done at $1160-1170{ }^{\circ} \mathrm{C}$ for $6 \mathrm{~h}$ in a muffle furnace in the air, keeping the sample for $1 \mathrm{~h}$ at $600{ }^{\circ} \mathrm{C}$ to remove the organic binder; $V_{\text {heat }}=250{ }^{\circ} \mathrm{C} / \mathrm{h}$.

The morphology of the HFMs was examined with a TM-1000 (Hitachi, Japan) scanning electron microscope. The gas tightness of the HFMs was approved by using a NORD-TEST ROT 3000 commercial penetrant (Helling GMBH, Germany) whose penetrating ability is comparable to gases.

The experimental setup is shown in Figure 2.

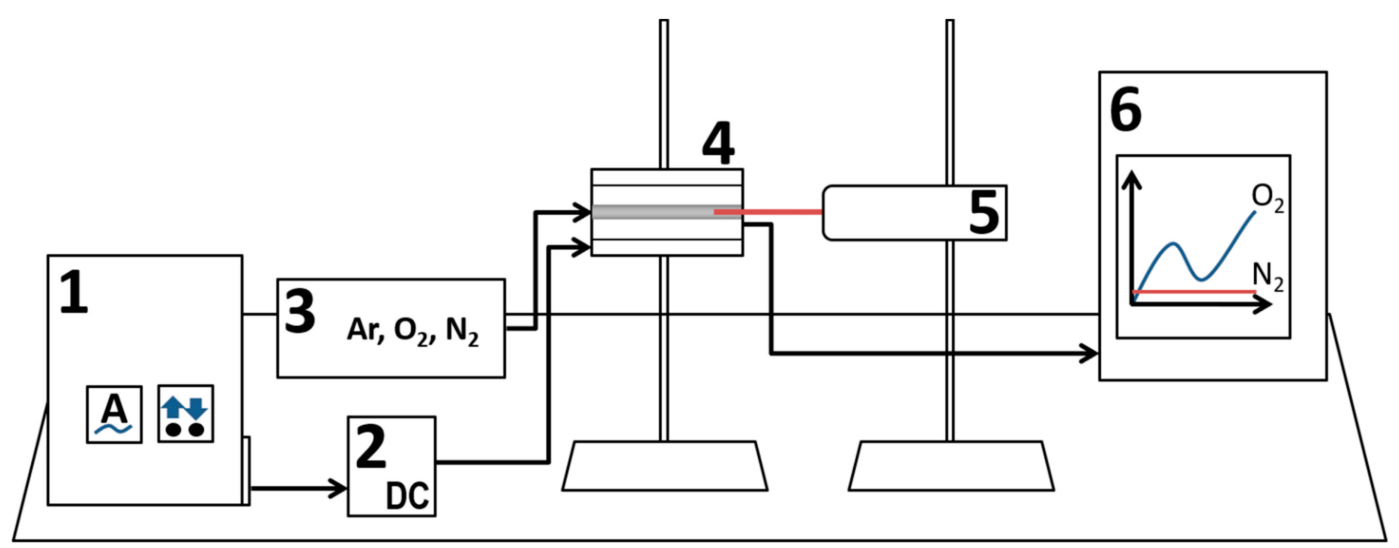

Figure 2. Installation for the study of the high-temperature oxygen permeability of hollow fiber membranes (HFMs): 1-AC source; 2-rectifier; 3-gas mixer; 4-reactor; 5-infrared pyrometer; and 6-QMS.

Direct AC heating was performed by means of an AC source (1). In the case of DC heating, a rectifier (2) was used. Gas flows ( $\mathrm{Ar}, \mathrm{O}_{2}, \mathrm{~N}_{2}$ ) were monitored with a UFPGS-4 gas mixer (3) (SoLO, Russia). The gases are fed into the reactor (4), thereby creating the internal and external areas of the membrane. The concentration of oxygen passing through the membrane was determined by quadrupole mass spectrometer (6) QMS 200 (SRS, USA). The temperature of the membrane was monitored by an IGA 300 infrared pyrometer (5) with an accuracy of $5^{\circ} \mathrm{C}$ (IMPAC, Germany). The spot size of pyrometer was $2.0 \mathrm{~mm}$. The summary flow of oxygenated Ar was controlled by a MARK flow sensor (SoLO, Russia).

In this experiment, the original reactor was used (Figure 3). 


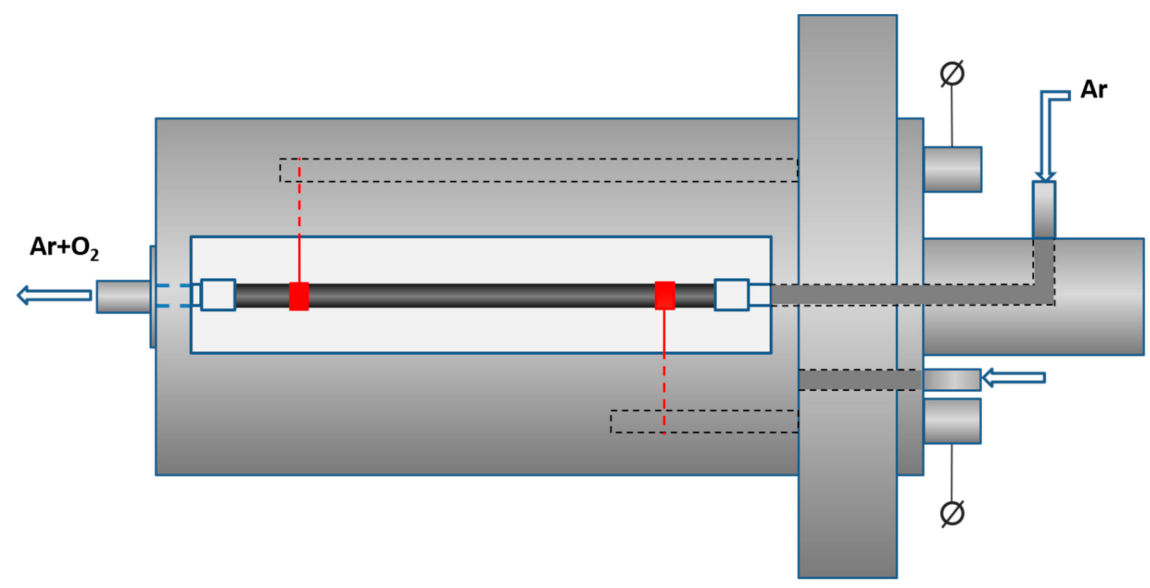

Figure 3. The reactor for AC/DC heating experiments.

The "Ar" and "Ar+O $\mathrm{O}_{2}$ " channels were connected with the HFMs through polymer tubes; the connections were sealed by heat-shrink tubes. A current-conducting reliable connection between the HFMs and the AC/DC source was provided by silver coating.

The study of high-temperature oxygen permeability was performed by using gas-tight BSCFM10 HFMs at $600-850{ }^{\circ} \mathrm{C}$ (with a step of $50{ }^{\circ} \mathrm{C}$ ) and oxygen partial pressures on the feed side, $\mathrm{pO}_{2.1}$, of $0.10-0.70 \mathrm{~atm}$ (with a step of $0.10 \mathrm{~atm}$ ).

Oxygen and nitrogen were supplied in various proportions inside the reactor, and argon was supplied into the membrane. The flow rate of the sweep gas $(90 \mathrm{ml} / \mathrm{min})$ and the flow rate of feed gas $(150 \mathrm{ml} / \mathrm{min})$ were constant throughout the experiment. These values and counter-current flow mode were selected earlier and determined as necessary and sufficient for the experiment, in particular for the uniform distribution of heat along the membrane. The controlled heating of the membrane was carried out by the current regulator, which ensured the necessary temperature regime during the experiment: $\mathrm{V}_{\text {heat }}=350{ }^{\circ} \mathrm{C} / \mathrm{h}$.

When the required temperature was reached, the oxygen pressure in the sweep gas $\left(p \mathrm{O}_{2.2}\right)$ was measured in a given range of partial oxygen pressures in the feed gas $\left(p \mathrm{O}_{2.1}\right)$, as indicated earlier, with a waiting time at each pressure for at least 5 minutes. Measurements were taken starting from the lowest temperature, as well as from the lowest partial pressure of oxygen at each temperature.

In order to describe the oxygen transport in the hollow fiber membranes, we propose a model based on the semi-empirical dependence of the oxygen flux $\left(\mathrm{JO}_{2}\right)$ on the partial pressures of oxygen, which is generally used in the case of planar membranes [9-13] and was rationalized by the oxygen transport model presented in [14]:

$$
J_{O_{2}}=\frac{p O_{2.1^{n}-p O_{2.2^{n}}}}{\frac{h}{D K}+\frac{2}{k_{a d s}}}=\gamma(T)\left(p O_{2.1^{n}}-p O_{2.2^{n}}\right)
$$

where $h$ is membrane thickness, $K=k_{\mathrm{ads}} / k_{\mathrm{des}}, k_{\mathrm{ads}}$ and $k_{\mathrm{des}}$ are the rate constants of the surface reactions, $\gamma(T)$ is a temperature factor associated with the limiting stage of oxygen transport (bulk diffusion coefficient $D$ and/or surface exchange constants $k_{\text {ads }}, k_{\text {des }}$ ), and $n$ is interpreted in various oxygen exchange models as an effective order of reaction for oxygen.

Assuming that the leakage of nitrogen and oxygen through pores or cracks was in accordance with Knudsen diffusion, the fluxes of leaked $\mathrm{N}_{2}$ and $\mathrm{O}_{2}$ were related by:

$$
J_{N_{2}}^{\text {Leak }}: J_{\mathrm{O}_{2}}^{\text {Leak }}=\sqrt{\frac{32}{28}} \times \frac{0.79}{0.21}=4.02
$$

For analysis, we used data in which the contribution from molecular oxygen due to leakage through micro-cracks into oxygen fluxes was less than $1 \%$. 


\section{Results and Discussion}

The obtained materials were characterized by means of XRD (Figure 4).

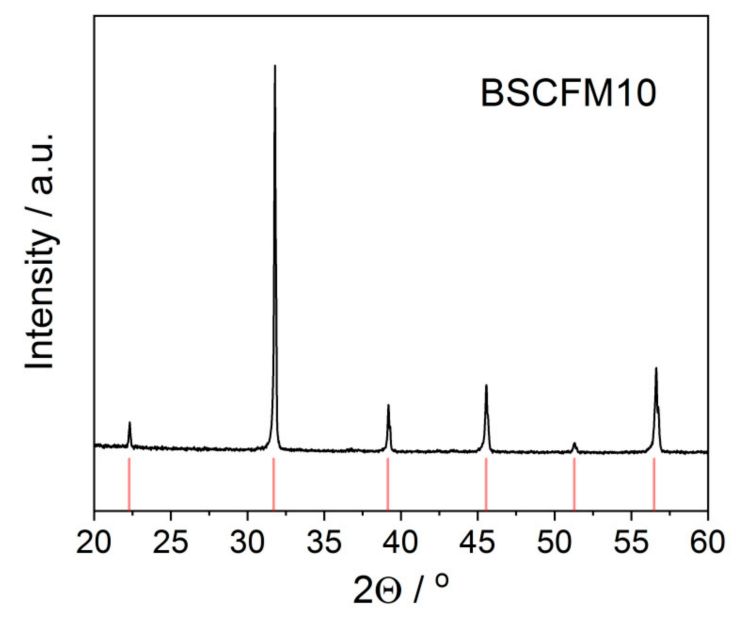

Figure 4. XRD patterns of the crushed hollow fiber membranes composed of $\mathrm{Ba}_{0.5} \mathrm{Sr}_{0.5} \mathrm{Co}_{0.7} \mathrm{Fe}_{0.2} \mathrm{Mo}_{0.1} \mathrm{O}_{3-\delta}$ (BSCFM10). Red peaks correspond to the cubic perovskite (Pm-3m) structure.

Direct AC/DC heating allowed us to control the temperature of the membrane itself. Thus, the longitudinal temperature gradient of the operating HFMs was studied (Figure 5). It was shown that increasing the sweep gas flow up to $90 \mathrm{ml} / \mathrm{min}$ did not significantly affect the gradient along the membrane.

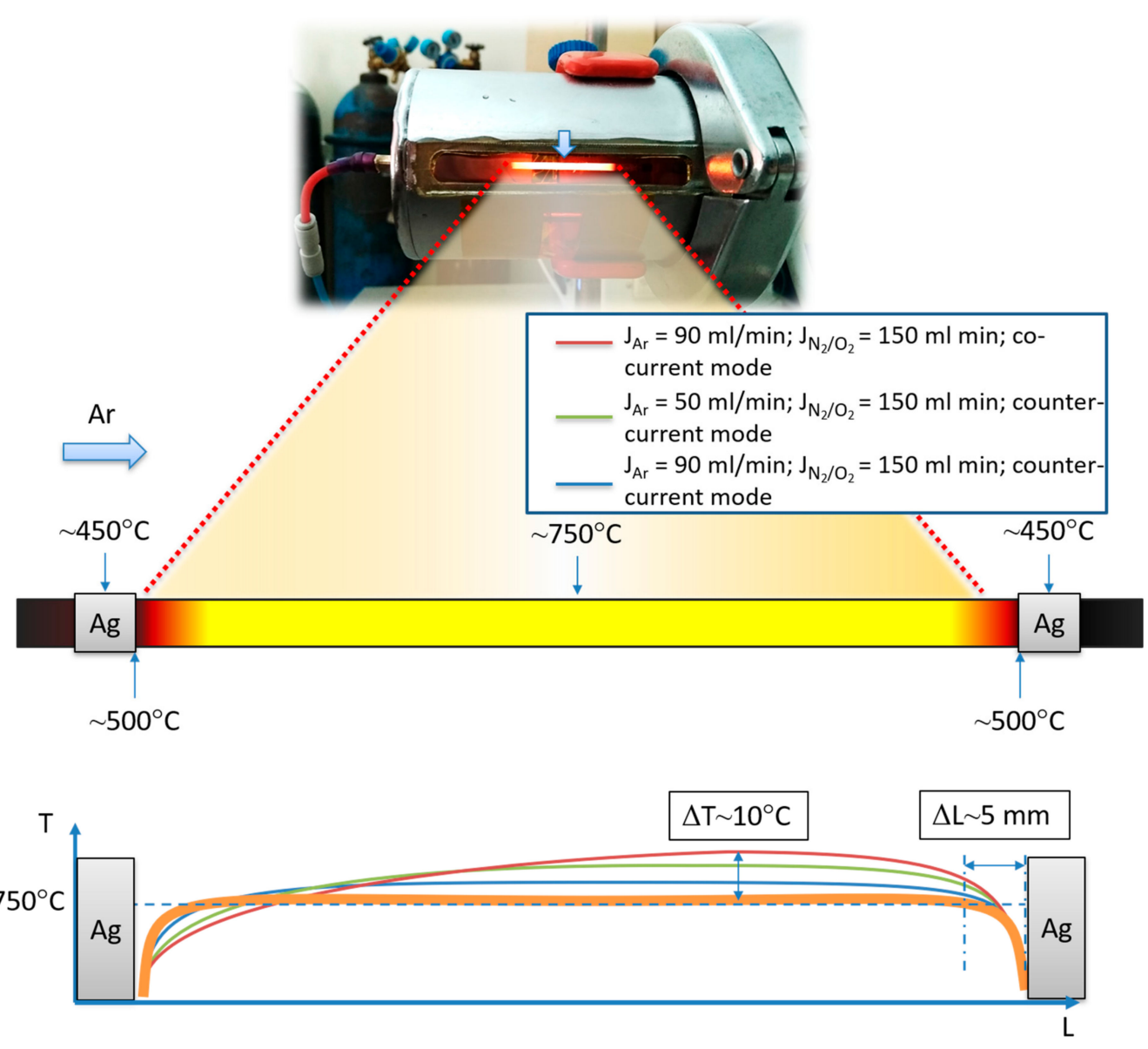

Figure 5. Longitudinal temperature gradient of the AC/DC-heated HFMs. 
Figure 6 shows the initial $p \mathrm{O}_{2}$ data of the AC- and DC-heated HFMs.
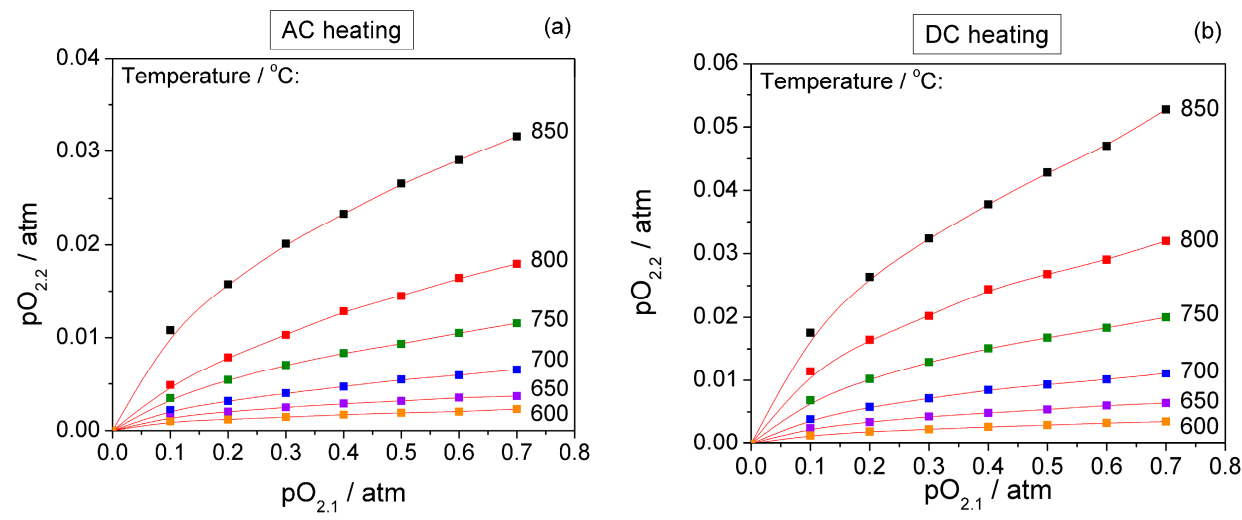

Figure 6. Dependence of oxygen partial pressure on the permeate side $\left(\mathrm{pO}_{2.2}\right)$ of $(\mathbf{a}) \mathrm{AC}$ - and (b) DC-heated HFMs on the temperature and oxygen partial pressure on the feed side $\left(\mathrm{pO}_{2.1}\right)$.

From the obtained data (Figure 6), the linearization of the measured oxygen fluxes was performed in the $\mathrm{pO}_{2.1}{ }^{0.5}-\mathrm{pO}_{2.2}{ }^{0.5}$ coordinates (Figure $7 \mathrm{a}, \mathrm{b}$ ) according to [15]. The values of $\gamma$ were obtained from the slope of the dependencies, and the activation energies ( $89 \pm 4$ and $94 \pm 2 \mathrm{~kJ} / \mathrm{mol}$ for the AC- and DC-heated HFMs, respectively) of the oxygen fluxes in the AC/DC-heated HFMs were determined from an Arrhenius plot (Figure 8a,b). The obtained values are close to literature data for $\mathrm{Ba}_{0.5} \mathrm{Sr}_{0.5} \mathrm{Co}_{0.75} \mathrm{Fe}_{0.2} \mathrm{Mo}_{0.05} \mathrm{O}_{3-\delta}$ samples [16].
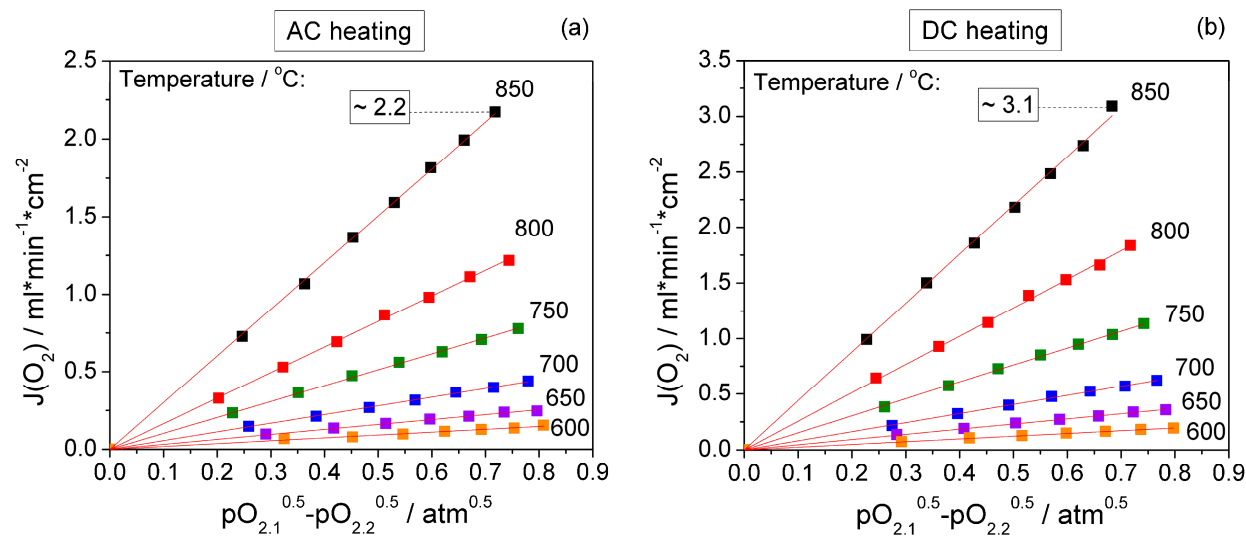

Figure 7. Linearization of oxygen flows and the Arrhenius dependence of the parameter $\gamma$ of (a) ACand (b) DC-heated BSCFM10 membranes.
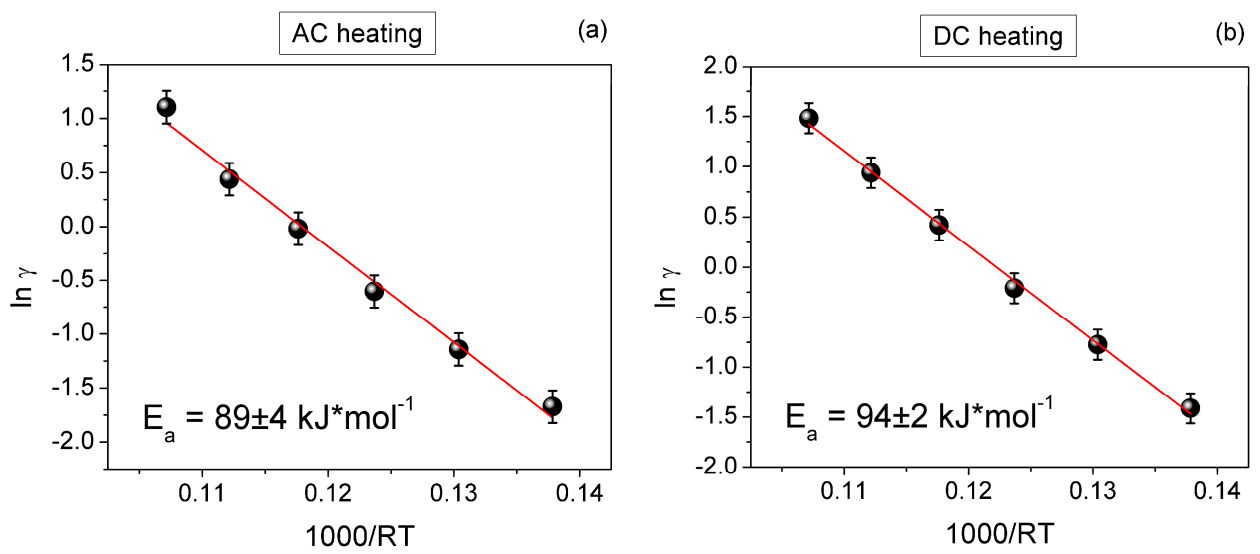

Figure 8. Arrhenius dependence of parameter $\gamma$ of (a) AC- and (b) DC-heated BSCFM10 membranes. 
In terms of activation energy values, the data obtained on the AC/DC HFMs can be considered the same. Nevertheless, there was a steady effect of increased oxygen fluxes (by $\sim 1.4$ times) when the membranes were heated by DC (Figure 9). An effect was discovered and further studies will be reported elsewhere.

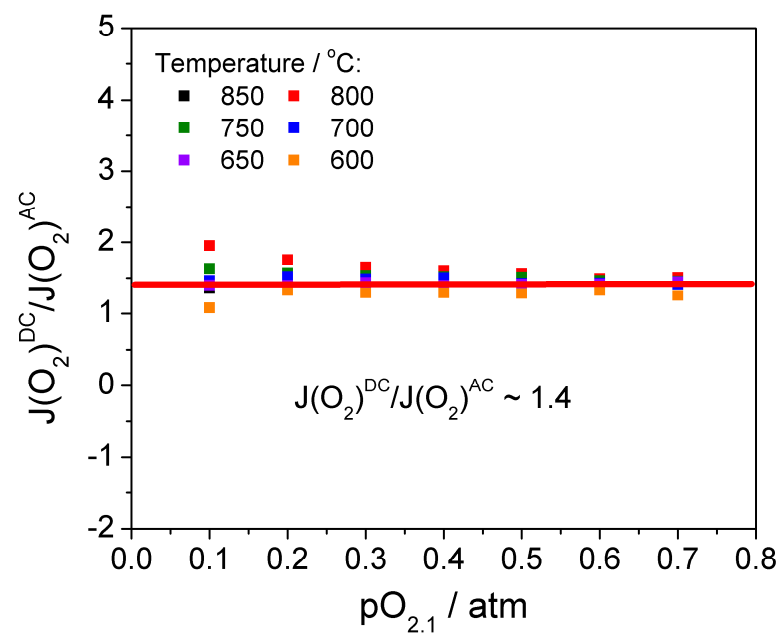

Figure 9. Comparison of the oxygen fluxes obtained by AC and DC heating.

The use of DC can theoretically promote the migration of cations, which can lead to an imbalance of composition. This hypothesis can be tested by a detailed study of the membrane surface after a long exposure of the sample under DC. We conducted a long-term experiment with HFMs heating in air at $800 \pm 10^{\circ} \mathrm{C}$. Using scanning electron microscopy, the membrane surface was studied prior to the experiment (Figure 10). After 310 h, surface images were taken along the length of the sample (Figure 11).

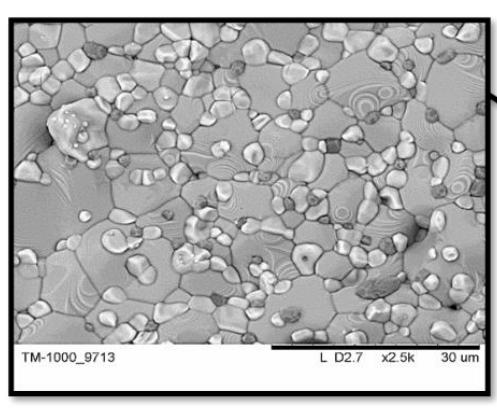

Inner surface
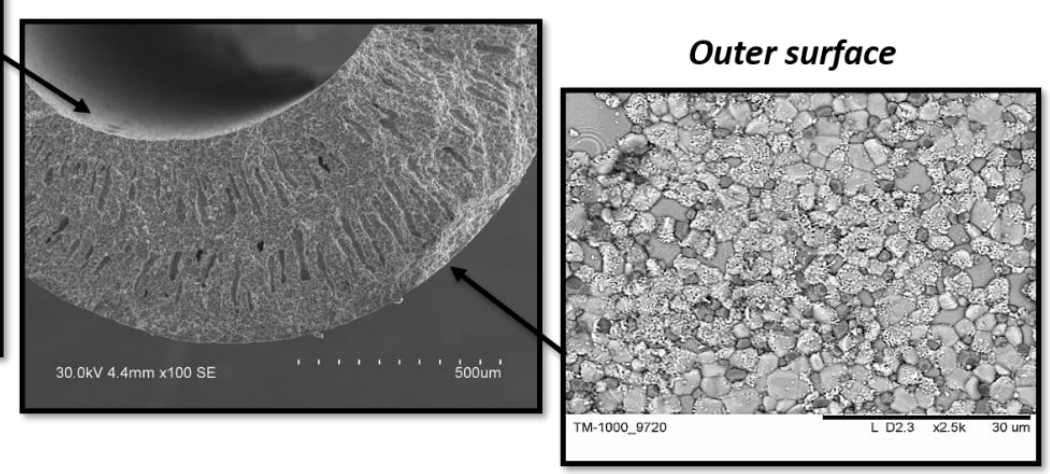

Figure 10. The surface of the BSCFM10 HFMs before the experiment.

After a detailed analysis of the membrane's surface with SEM, we concluded that the surface was uniform over the entire area; a typical image is shown in Figure 10.

As can be seen from the SEM images, the membrane surface lost its uniformity. It can be assumed that use of direct DC heating leads to degradation of the membrane, as opposed to using direct AC heating [6]. In terms of long-term experiments such difference can lead to a significant negative effect on the membrane. 


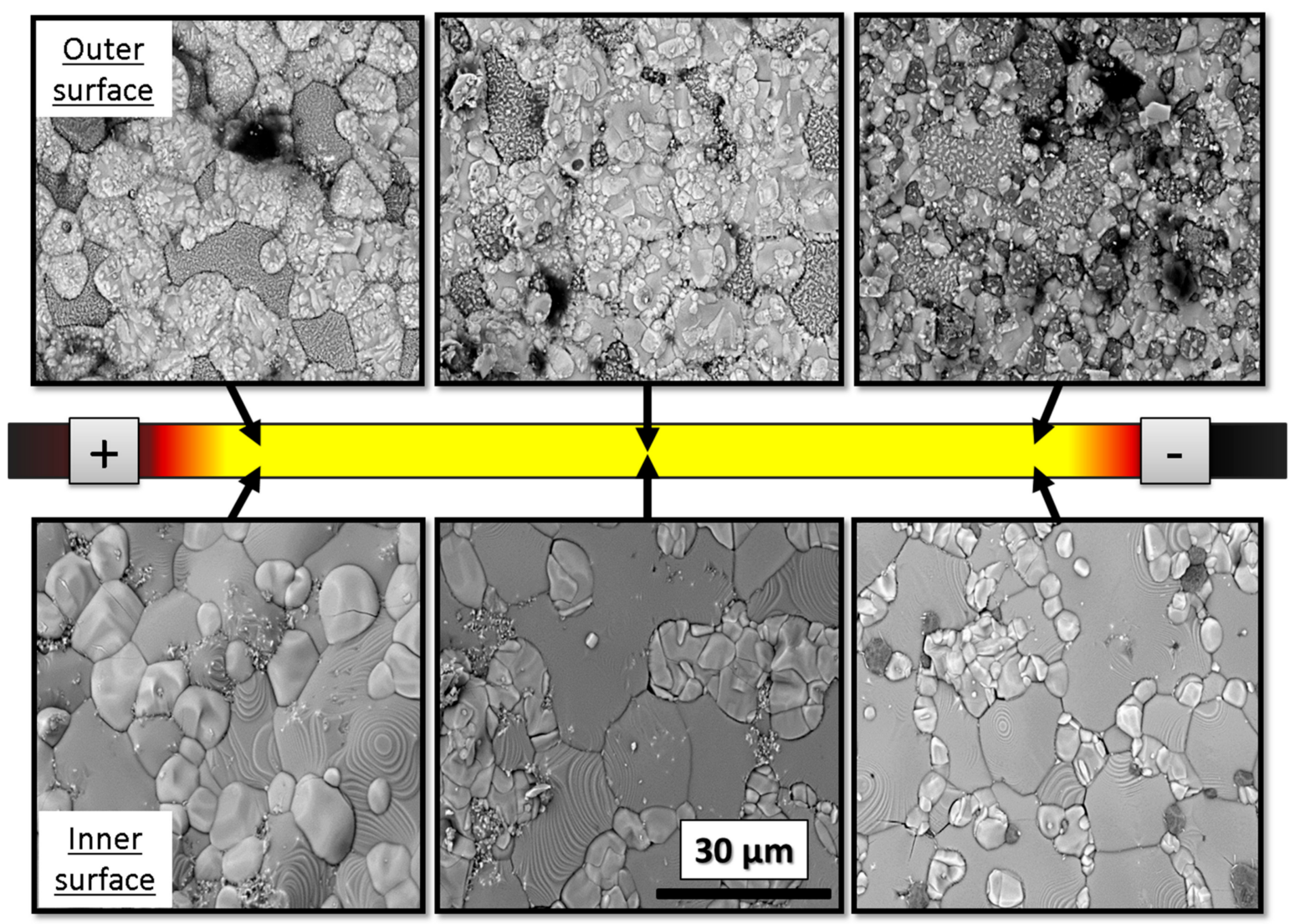

Figure 11. The surface of BSCFM10 membrane after experiment.

\section{Conclusions}

The present paper is a continuation of works related to the direct heating of oxygen transport membranes. Comparative data on the direct resistive heating of oxygen transport membranes (OTM) by alternating and direct electric current are presented for the first time.

Analyzing the data obtained in the study of various heating methods, we can draw the following conclusions:

- $\quad$ The direct heating technique allowed us to study the longitudinal temperature gradient of the operating HFMs.

- $\quad$ Increasing the sweep gas flow up to $70 \mathrm{ml} / \mathrm{min}$ did not significantly affect the gradient along the membrane.

- $\quad$ The activation energies determined from Arrhenius plot were $89 \pm 4$ and $94 \pm 2 \mathrm{~kJ} / \mathrm{mol}$ for the AC- and DC-heated HFMs, respectively.

- In the short-term experiment with direct current, a significant positive effect on the oxygen transport was found, whereas the sample exposure under direct current for a long period of time had a significant negative effect on the microstructure of the membrane.

Author Contributions: Conceptualization, M.P. and A.N.; methodology, A.T.; software, M.S.; validation, M.P. and S.B.; formal analysis, A.B.; investigation, I.K.; resources, M.P.; data curation, I.K. and A.V.; writing-original draft preparation, I.K.; writing - review and editing, M.P.; visualization, S.B.; supervision, M.P.; project administration, A.N.; funding acquisition, A.N. All authors have read and agreed to the published version of the manuscript.

Funding: This research was carried out within the state assignment to ISSCM SB RAS (project AAAA-A17-117030310277-6).

Conflicts of Interest: The authors declare no conflict of interest. 


\section{References}

1. Ten Elshof, J.E.; van Hassel, B.A.; Bouwmeester, H.J.M. Activation of methane using solid oxide membranes. Catal. Today 1995, 25, 397. [CrossRef]

2. Marques, F.M.B.; Kharton, V.V.; Naumovich, E.N.; Shaula, A.L.; Kovalevsky, A.V.; Yaremchenko, A.A. Oxygen ion conductors for fuel cells and membranes: Selected developments. Solid State Ion. 2006, 177, 1697. [CrossRef]

3. Sunarso, J.; Baumann, S.; Serra, J.M.; Meulenberg, W.A.; Liu, S.; Lin, Y.S. Mixed ionic-electronic conducting (MIEC) ceramic-based membranes for oxygen separation. J. Membr. Sci. 2008, 320, 13. [CrossRef]

4. Leo, A.; Liu, S.; Diniz da Costa, J.C. Development of mixed conducting membranes for clean coal energy delivery. Int. J. Greenh. Gas Con. 2009, 3, 357. [CrossRef]

5. Mahato, N.; Banerjee, A.; Gupta, A.; Omar, S.; Balani, K. Progress in material selection for solid oxide fuel cell technology: A review. Prog. Mater. Sci. 2015, 72, 141. [CrossRef]

6. Popov, M.P.; Bychkov, S.F.; Nemudry, A.P. Direct AC heating of oxygen transport membranes. Solid State Ion. 2017, 312, 73. [CrossRef]

7. Popov, M.P.; Gainutdinov, I.I.; Bychkov, S.F.; Nemudry, A.P. New approaches for enhancement of oxygen fluxes on hollow fiber membranes. Mat. Today Proc. 2017, 4, 11381. [CrossRef]

8. Hancke, R.; Larsen, T.V.; Xing, W.; Li, Z.; Fontaine, M.-L.; Norby, T. Ohmically heated ceramic asymmetric tubular membranes for gas separation. J. Membr. Sci. 2018, 564, 598. [CrossRef]

9. Tong, J.; Yang, W.; Cai, R.; Zhu, B.; Xiong, G.; Lin, L. Investigation on the structure stability and oxygen permeability of titanium-doped perovskite-type oxides of $\mathrm{BaTi}_{0.2} \mathrm{Co}_{\mathrm{x}} \mathrm{Fe}_{0.8-\mathrm{x}} \mathrm{O}_{3-\delta}(\mathrm{x}=0.2-0.6)$. Sep. Pur. Tech. 2003, 32, 289-299. [CrossRef]

10. Savinskaya, O.A.; Nemudry, A.P. Oxygen permeability and structural features of $\mathrm{SrFe}_{1-\mathrm{x}} \mathrm{W}_{\mathrm{x}} \mathrm{O}_{3-\delta}$ membranes. J. Membr. Sci. 2014, 459, 45-51. [CrossRef]

11. Liu, S.; Gavalas, G.R. Oxygen selective ceramic hollow fiber membranes. J. Membr. Sci. 2005, 246, $103-108$. [CrossRef]

12. Artimonova, E.V.; Savinskaya, O.A.; Nemudry, A.P. Effect of B-site tungsten doping on structure and oxygen permeation properties of $\mathrm{SrCo}_{0.8} \mathrm{Fe}_{0.2} \mathrm{O}_{3-\delta}$ perovskite membranes. J. Eur. Ceram. Soc. 2015, 35, 2343-2349. [CrossRef]

13. Li, Q.; Zhu, X.; He, Y.; Yang, W. Oxygen permeability and stability of $\mathrm{BaCe}_{0.1} \mathrm{Co}_{0.4} \mathrm{Fe}_{0.5} \mathrm{O}_{3-\delta}$ oxygen permeable membrane. Sep. Pur. Tech. 2010, 73, 38-43. [CrossRef]

14. Popov, M.P.; Starkov, I.A.; Bychkov, S.F.; Nemudry, A.P. Improvement of $\mathrm{Ba}_{0.5} \mathrm{Sr}_{0.5} \mathrm{Co}_{0.8} \mathrm{Fe}_{0.2} \mathrm{O}_{3-\delta}$ functional properties by partial substitution of cobalt with tungsten. J. Membr. Sci. 2014, 469, 88-94. [CrossRef]

15. Geankoplis, C.J. Transport Processes and Unit Operations, 3rd ed.; Prentice Hall: Englewood Cliffs, NJ, USA, 1993.

16. Shubnikova, E.V.; Popov, M.P.; Chizhik, S.A.; Bychkov, S.F.; Nemudry, A.P. The modeling of oxygen transport in MIEC oxide hollow fiber membranes. Chem. Eng. J. 2019, 372, 251-259. [CrossRef]

(C) 2019 by the authors. Licensee MDPI, Basel, Switzerland. This article is an open access article distributed under the terms and conditions of the Creative Commons Attribution (CC BY) license (http://creativecommons.org/licenses/by/4.0/). 